\title{
A Study on the Demographics and Personality Traits of Unemployed Trainees from Vocational Training Influence on their Learning Motives
}

\author{
${ }^{1}$ Chang, Jen-Chia, ${ }^{2}$ Chiang, Po -Ying \\ National Taipei University of Technology, Taiwan
}

\begin{abstract}
This study aimed to explore whether or not the demographics and personality traits of unemployed trainees from vocational training have an impact on learning motivation. Unemployed people trainees from vocational training in Hualien, Taiwan were adopted as samples of research participants for questionnaire surveys. A total of 272 valid questionnaires were recovered, which underwent hierarchical regression analysis. Findings show: 1. the female trainees from vocational training comprised the majority. In addition to middleold aged trainees, the 21-30 years old age group also took up a considerable proportion. Regardless of age and gender, the trainees were expected to learn new skills and develop a second specialty; 2. the personality traits of the trainees and learning motivation showed a partially significant correlation; 3. Under controlled demographics, personality traits also showed a partially significant impact on learning motivation. Finally, based on the research results, practical management implications were put forth in this study. The research limitations and future research recommendations were further specified.
\end{abstract}

Keywords: unemployed trainees for vocational training, personality traits, learning motivation.

\section{INTRODUCTION}

By participating vocational training, the manpower will be enhanced. Most countries have active labor market programs that provide training for the unemployed. The programs are intended to assist the unemployed in obtaining jobs faster and mitigate their wage losses (Hebbar, 2006). According to the statistics of the Directorate-General of Budget, the average unemployment rate in Taiwan in 2014 is $3.96 \%$, with unemployed persons totaling 457,000 people (The Directorate-General of Budget, Executive Yuan, 2015). In consideration to the vanishing work model due to globalization, Taiwan is faced with increases in long-term unemployment ratios (Research Development and Evaluation Commission, Executive Yuan, 2012). Unemployment is one of the major sources in inequality in modern societies - the major distributional gain from any reduction in unemployment (Neubäumer, 2012). On the other hand, regardless of national income, unemployment remains an issue of focus for the government and society (Lee, Chang, Wang, Guo, and Wu, 2005). In order to reduce unemployment rates effectively, increase labor force, train laborers that demonstrate learning power, professionalism, innovation, and resilience, it seems vocational training has become increasingly important. From 1990 to 2013, government-run vocational training institutions have conducted vocational training of 642,417 people. Taking 2014 for instance, the Work Force Development Agency has conducted vocational training for unemployed persons through self-management, outsourcing, subsidies, and other means, totaling 64,259 people (The Ministry of Labor, 2015).

Since the learning motivation of trainees has a tremendous impact on training learning effectiveness (Chang, 2013; Chang and Chiang, 2013) and that the researcher discovered varied learning motivations based on his observation of sites of vocational training courses for unemployed persons and the course of trainees' learning during training. On the other hand, the varied degrees of continuing to learn new skills and knowledge ultimately led to differed learning effectiveness. Whether or not the trainees' different personality traits affected learning motivation is one of the research motivations in this study. Also, whether or not the trainees' different demographics and personality traits had a significant correlation with the predictive power of the overall learning motivation is the second research motivation in this study. 
In view of the above, this study aimed to gain an insight into: 1 . The correlation between personality traits and learning motivation; 2. Assessments on the predictive power of the different demographics and personality traits of trainees on learning motivation. First, literature related to vocational training for unemployed persons, personality traits, and learning motivation were explored in order to establish the research framework. Then, the questionnaire on the personality traits and learning motivation of trainees from vocational training were designed. Data analysis was conducted through quantitative analysis. Finally, based on the analysis results, research findings and recommendations were put forth.

\section{LITERATURE REVIEW}

\subsection{Vocational Training for Unemployed Persons}

Unemployed vocational training provides effective assistance for returning to the labor market. The purpose of vocational training for unemployed persons is to enhance the employment skill of unemployed persons. The goal is to help trainees immediately find a job after receiving training (The Ministry of Labor, 2015). It is a relatively more effective way to resolve structural unemployment, in preparation for employment opportunities when the next wave of economic recovery hits.

The term "unemployed" refers to people aged over 15 who meet the following criteria within the data standard week: No job, ready to work at any time, currently seeking a job, and already found a job but waiting for results. Unemployed persons also include those waiting to resume work and those who have found a job but have not begun working or getting paid (The Directorate-General of Budget, Executive Yuan, 2015). Vocational training refers to various work skills, relevant knowledge, and work attitude related training for workers ready to start working, incoming workers who are already working, or on-job workers (Tan, 2012). The value of vocational training lies in helping unemployed persons to effectively return to the workplace and resolve the unemployment problem. As for factors contributing to post-training effectiveness, further exploration is needed. In this study, unemployed persons refer to middle-old aged, indigenous, individuals on living subsidies, long-term unemployed, unemployed foreign and Chinese spouses, individuals with middle-low income, vocational trainees in Hualien area; and vocational training refers to pre-employment training implemented for unemployed nationals, with the exclusion of vocational training implemented for employed nationals.

\subsection{Personality Traits}

Personality Traits will affect the work motivation and the work performance. Costa and McCrae (1989) believe that individuals' continuous and consistent characteristic reactions expressed under different situations are known as "personality traits". Chang Chun-Hsing believes that an individual's personality is a quality that distinguishes the individual from others when adapting to people, self, and all environments (Chang, 1998). In recent years, among relevant research fields, the personality trait dimensions developed according to the trait theory of Allport and Cattell are generally applied in psychology, management, and sociology (Digman, 1990). Tupes and Christal (1961) examined the research results of Cattell and found five factors that demonstrate strong relatedness. Goldberg (1990) officially named the five factor models "Big Five" and define the five factors dimensions as: extraversion, agreeableness, conscientiousness, neuroticism, and openness to experience (Brigges, 1992). The research by McCrae and John (1992) states: The model should prove useful both for individual assessment and for the elucidation of a number of topics of interest to personality psychologists. In order for respondents to answer questions more easily and enhance validity, Saucier (1994) simplified Goldberg's 100 questions of personality trait scale and developed Mini-Marker scale. Mini-marker scale features the use of single adjectives and few questions. It only takes five minutes to answer questions, and thus it is widely accepted and used scale (Lin, Chiu, and Hsieh, 2001).

\subsection{Learning Motivation}

Both intrinsic motivation and extrinsic motivation affect individual learning motivation. Houle, a scholar engaged in learning motivation related studies in the early days divided learners into three motivation types based on his three-way typology, namely, goal orientation, activity orientation, and learning orientation (Huang, 1996). Boshier (1971) also divided adults' learning motivation into six factors, namely, social contact, social stimulation, career development, social services, external expectations, and cognitive interest. The most important motivation orientations for general adjust 
learners are: cognitive interest and career development (Fu-Shun Huang, 1996). Lepper (1985) believes that the inherent nature of learners' motivation is triggered by learners' personal preferences, feelings, and interest. Hence, learning motivation is influenced by personal factors and external environments. Personal factors include: goals, beliefs, and self-concept; factors affected by external environments include: environment, expectations of others, social values, and so on (Tharenou,2001). Motivation is the force that arouses enthusiasm and persistence to prove a certain cause of action (Dorothea, 2013). Therefore, learners with strong motivation will be more committed to learning, which will in turn affect the effectiveness of learning activities.

\subsection{Studies Related to the Impact of Personality Traits on Learning Momtivation}

Learning motivation is affected by personality traits of human. Winter, John, Stewart, Klohnen, and Duncan (1998) pointed out that traits and motives interact in the prediction of behavior: Traits channel the behavioral expression of motives throughout the life course, and learners influenced by their personality traits produce different learning motivations (Salgado, 1997). Personality traits affect trainees' personal expectations for trainings and self-efficacy, as well as their work attitude and career planning, which in turn affect their learning motivation (Noe, 1991; Tracey and Tews,1995). The study of Mount and Barrick (1994) show that "extraversion" and "openness to experience" are effective predictive variables of the familiarity towards various types of vocational training. Major, Turner and Fletcher, (2006) pointed out in their study that proactive personality, openness, extraversion, and conscientiousness predicted motivation to learn. In addition, motivation to learn was positively related to objectively assessed development activity. Proactive personality, extraversion, and openness had significant indirect links to development activity. Colquitt, J. A., Lepine, J. A., and Noe, R. A. (2000) believe personality variables had a moderate to strong relationship with motivation to learn as well as the learning outcomes.

In summary of the above emperical findings, individuals' personlity traits are said to be under the influence of learning motivation, while learning motivation also affects the work performance and learning effectiveness of enterprises and education training fields. Therefore, this lead to the following hypothesis in this study: Hypothesis 1: The personality traits and learning motivation of unemployed trainees from vocational training are significantly correlated; Hypothesis 2: Their demographics and personality traits have a significant impact on learning motivation.

\section{RESEARCH DESIGN}

\subsection{Research Framework}

In this study, the relevance and differences between the personality traits and learning motivation of unemployed trainees from vocational training were explored based on the research questions and related literatures. The research framework is as shown in Fig. 1. This study proposed two hypothesizes were be test to understand the differences between the personality traits and learning motivation of unemployed trainees as follows.

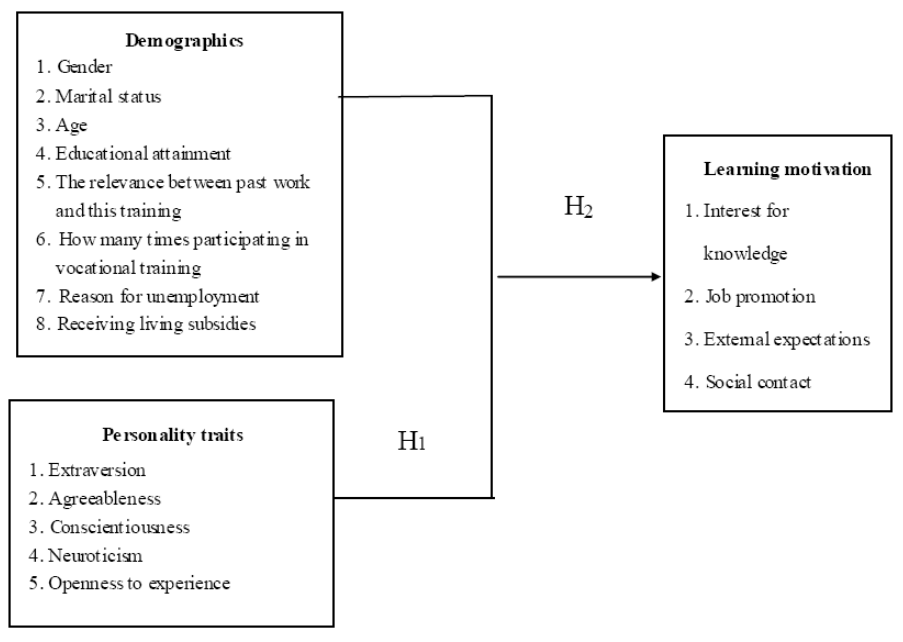

Figure1. Research framework 
Hypothesis 1: The personality traits are significantly positive correlated to learning motivation of unemployed trainees from vocational training.

Hypothesis 2: Their demographics and personality traits have a significant positive impact on learning motivation.

\subsection{Research Participants}

In this study, unemployed trainees from vocational training were adopted as research participants. Convenience sampling was used to select one class each from three vocational training institutions for unemployed among the classes conducted. First, the training conduction units commissioned by the Vocational Training Council was contacted by phone. After obtaining its consent to undergo questionnaire surveys, prior to the formal questionnaire surveying, pre-test questionnaire surveys were conducted. A total of 87 questionnaire copies were distributed, of which 80 copies were recovered and 4 invalid copies were eliminated. There were 76 valid copies, accounting for the effective recovery rate of 95\%. The formal questionnaire in this study was implemented from September, 2014 to December, 2014 through convenience sampling on commenced classes that have not yet completed training conduction. In order to increase the effective recovery rate, the author personally distributed and recovered the questionnaires. A total of 307 copies were distributed, 35 of which were invalid and eliminated and 272 were valid copies, the effective rate of $89 \%$.

\subsection{Instrument}

The questionnaire survey method was adopted in this study. First, based on literatures, the connotation, characteristics, and related theories of personality traits and learning motivation were summarized to form the research framework. Then, the questionnaire dimensions were set based on the research problems. Finally, the questionnaire contents and questions were designed. The content of this questionnaire are divided into: Part 1: Personal information; Part 2: Personality traits; Part 3 Learning motivation. Personal information includes items such as: Gender, marital status, age, educational attainment, whether or not past work is related to the job category of the training, how many times participating in vocational training, and if receiving subsides or not.

As for the questionnaire of personality traits, the short adjectives scale in Saucier Big Five minimakers was used to self-compile personality trait related dimensions; including: extraversion, agreeableness, conscientiousness, neuroticism, and openness to experience. As for the questionnaire of learning motivation, domestic and foreign literatures as well as unemployed trainees from vocational training served as the basis for self-compiling the learning motivation scale using Fu-shun Huang's "The motivation of adults to participate in continuing education motivation scale", a total of 20 questions. Likert's 5-point scale was used to measure the scores, including dimensions such as interest for knowledge, job promotion, external expectations, and social contact.

\subsection{Scale Reliability and Validity Test}

Targeting the personality traits and the appropriateness and relevance of the learning motivation dimensions established, the questionnaire contents were revised and reviewed by five experts and scholars in order to establish the content validity of the expert questionnaire. Then, through item analysis and factor analysis, the validity was verified. In this study, Cronbach's $\alpha$ reliability analysis was adopted to verify the internal consistency of the variables in the questionnaire. The internal consistency (IC) was exceeding .7 that indicated high internal consistency; in other side, internal consistency lower than .35 indicated that low internal consistency. In this research questionnaire, the Cronbach's $\alpha$ coefficient of personality traits was .7 , the Cronbach's $\alpha$ coefficient was .8 for learning motivation, the Cronbach's $\alpha$ for the overall scale was .767 , thus indicating good consistency. The questionnaire therefore has good reliability.

In order to confirm the construct validity and reliability of the "personality traits" and "learning motivation" scales during the tests, the exploratory factor analysis, EFA was used in this study, and the Cronbach's $\alpha$ coefficient was calculated to evaluate the reliability and validity of the scales.

(1) KMO and Bartlett's Test

Before conducting factor analysis, the research data was first examined to determine its suitability for factor analysis execution. Kaiser-Meyer-Olkin measure of sampling adequacy, KMO was used to test 
the coefficient of net correlation (The closer KMO is to one, the lower the coefficient of net correlation and the better result in extracting common factors using factor analysis). Additionally, Bartlett's test of sphericity was adopted to verify whether or not the coefficient of correlation was significantly higher than 0 . The KMO values of the two scales "personality traits" and "learning motivation" were .760 and .805 respectively. The values obtained from Bartlett's test of sphericity all reached significant standards $(p<.001)$, thus indicating all the data of the two scales is suitable for factor analysis execution.

\section{(2) Personality Trait Scale}

Factor analysis on the personality trait scale was conducted six times. Nine questions were eliminated in order. The factor analysis results after the final rotation are as follows:

The eigenvalue of "extraversion" was 3.62, the explained variance was $11.67 \%$, the factor loads of the questions were between .59 and .78 ; the eigenvalue of "agreeableness" was 4.92 , the explained variance was $15.86 \%$, the factor loads of the questions were between .65 and .79; the eigenvalue of "conscientiousness" was 2.35 , the explained variance was $7.57 \%$, the factor loads of the questions were between .65 and .82; the eigenvalue of "neuroticism" was 4.32 , the explained variance was $13.93 \%$, the factor loads of the questions were between .63 and .87 ; the eigenvalue of "openness to experience" was 2.68 , the explained variance was $8.64 \%$, the factor loads of the questions were between .49 and .79 . The factor loading of all the questions in the personality trait scale was higher than the standard .40. Moreover, the cumulative explained variance of all the sub-scales was $57.67 \%$, which is higher than 50\%, indicating the common factors extracted are reliable (Ming-lung Wu, 2009). Hence, the personality trait scale designed in this study is said to possess good construct validity. In terms of reliability, "the Cronbach's $\alpha$ was .812 for "extraversion", .889 for "agreeableness", .702 for "conscientiousness", .885 for "neuroticism", and .713 for "openness to experience". The reliability of all the sub-scale exceeded .70, thus indicating the questions in different dimensions of the scale possessed good internal consistency.

\section{(3) Learning Motivation Scale}

Factor analysis on learning motivation scale was conducted twice. Only question 4 and 19 were eliminated. The factor analysis results after the final rotation are as follows:

The eigenvalue of the "interest for knowledge" sub-dimension was 2.46 , the explained variance was $13.68 \%$, the factor loads of the questions were between .55 and .87 ; the eigenvalue of the "job promotion" sub-dimension was 3.23 , the explained variance was $17.92 \%$, the factor loads of the questions were between .57 and .79. The eigenvalue of the "external expectations" sub-dimension was 3.43, the explained variance was $19.07 \%$, the factor loads of the questions were between .65 and .82 ; the eigenvalue of the "social contact" sub-dimension was 2.73 , the explained variance was $15.14 \%$, the factor loads of the questions were between .53 and .82 . The cumulative explained variance of the all the sub-scales was $65.81 \%$, which is higher than $50 \%$, indicating the questions in the different dimensions of the scale possessed good internal consistency.

\section{Data Analysis and Results}

The quantitative analysis method was adopted in this study for data analysis. After recovering the questionnaires and eliminating those with incomplete data, the questionnaire data underwent coding and archiving. Statistical package software SPSS was used in data analysis. The analysis methods include: descriptive statistics, reliability and validity analysis, Pearson product-moment correlation, and multiple regression analysis. The data analysis results are as follows:

\subsection{The Distribution of Basic Information}

In this study, frequency distribution was mainly used to compute the numbers and percentages of the respondents in terms of their demographic variables" (including gender, marital status, age, educational attainment, the correlation between past job and vocational training, the number of times participating in vocational training, reason for unemployment, receiving living subsides) in order to understand the distribution of the trainees' basic information. 
The respondents comprised mainly of "females", a total of 191 people (70.2\%), which outnumbered "males" that totaled 81 people $(29.8 \%)$. As for marriage status, "married" comprised the marmite, accounting for 140 people (51.5\%), followed by "single", accounting for 96 people (35.3\%), "other (divorced or loss of marriage), accounting for 36 people (13.2\%). In terms of age, the trainees falling under "41-50 years old" comprised the majority, accounting for 78 people $(28.7 \%)$, the least fell under "20 years old (or under), accounting for 22 people (8.1\%). In educational attainment, "senior high school/vocational high school" graduates comprised the majority, accounting for 161 people $(59.2 \%)$. As for the relevance between past job the category of training participated, trainees under "completely unrelated" comprised the majority, accounting for 196 people (72.1\%), followed by "slightly related", accounting for 61 people (22.4\%), "highly related", accounting for 15 people $(5.5 \%)$. As for the number of times participating in vocational training of unemployed persons, "first time" comprised the majority, accounting for 166 people (61.0\%), followed by "second time or more", accounting for 106 people (39.0\%) In addition, in terms of reason for unemployment, "voluntary unemployment" comprised for the majority, accounting for 193 people (71.0\%), followed by "involuntary unemployment", accounting for 79 people (29.0\%). Meanwhile, more people fell under "receiving life subsidies", accounting for 241 people (88.6\%), followed by "not receiving living subsidies", accounting or 31 people (11.4\%).

\subsection{The Relevance between Personality Traits and Learning Motivation}

Concerning the correlations among the dimensions of the "personality traits" and "learning motivation" scales, the research results show that, the correlation coefficient of "extraversion" and "job promotion" reached significant standards $r=-.13, p<.05$. the correlation coefficients were negative values, thus indicating the higher the trainees' personality trait "extraversion", their lower the learning motivations "job promotion". The correlation coefficient of "agreeableness" and "external expectations" reached significant standards $(r=-.17, p<.05)$. The correlation coefficients were negative values, thus indicating the higher the trainees' personality trait "agreeableness", the lower the learning motivation of "external expectations". The correlation coefficients of "interest for knowledge" and "external expectations" reached significant standards $(r=.12$ '.14, $p<.05)$, and the correlation coefficients were positive values, thus indicating the higher the trainees' personality trait "neuroticism", the higher the degree of learning motivations "interest for knowledge" and "external expectations". The correlation coefficients of "openness to experience", "job promotion", and "external expectations" reached significant standards $(r=.18 \& .18, p<.05)$, the correlation coefficients were positive values, thus indicating the higher the degree of the trainees' "openness to experience" personality trait, the higher the learning motivations "job promotion" and "external expectations".

\subsection{The Impact of the Personality Traits of Trainees on Overall Learning Motivation}

The impact of personality traits on overall learning motivation is as shown in Table 1. In the multiple regression model, the overall $\mathrm{F}$ test reached significant standard $(F=3.40, p<.05)$, signifying the explanatory power of the regression model $\left(R^{2}=.060\right)$ possessed statistical significance and indicating all the independent variables can jointly and significantly affect the dependent variable "overall learning motivation". Additionally, the explanatory power is $6.0 \%$.

Table1. The summary of the regression coefficient summary table of trainees' personality traits affecting the overall learning motivation

\begin{tabular}{|l|l|l|l|l|l|}
\hline Independent variables & $\begin{array}{l}\text { Unstandardized } \\
\text { regression } \\
\text { coefficient }(B)\end{array}$ & $\begin{array}{l}\text { Standard error } \\
\text { S.E. }\end{array}$ & $\begin{array}{l}\text { Standard } \\
\text { regression } \\
\text { coefficient }(\beta)\end{array}$ & t value & $p$ value \\
\hline Intercept & 3.58 & 0.52 & & $6.85^{* * *}$ & $<.001$ \\
\hline Extraversion & -0.04 & 0.06 & -.04 & -0.65 & .519 \\
\hline Agreeableness & -0.08 & 0.06 & -.09 & -1.41 & .161 \\
\hline Conscientious & 0.02 & 0.06 & .02 & 0.32 & .746 \\
\hline Neuroticism & 0.06 & 0.05 & .09 & 1.33 & .185 \\
\hline Openness to experience & 0.21 & 0.08 & .17 & $2.72^{* *}$ & .007 \\
\hline$R^{2}$ & .060 & & & & \\
\hline$F$ & $3.40 * *$ & & & & \\
\hline$p$ & .005 & & & & \\
\hline
\end{tabular}

$* p<.05, * p<.01, * * * p<.001$ 
The t-test results show that the regression coefficient of "openness to experience" reached significant standard $(\beta=.17, p<.05)$, the regression coefficient is a positive value, an indication that the higher the degree of the trainee's personality trait in the aspect of openness to experience, the higher the degree of overall learning motivation. On the other hand, the regression coefficients of "extraversion", "agreeableness", "conscientiousness", and "neuroticism" did not reach significant standards ( $p>.05)$, thus indicating the trainees' degree of personality traits in these aspects is unable to effective affect the degree of "overall learning motivation.

\subsection{The Impact of the Demographics and Personality Traits of Trainees on Overall Learning Motivation}

Table 2 shows that Model 1 first conducted regression analysis using the "demographic variables" (including gender, marital status, age, educational attainment, relevance between past job and vocational training, number of times participating in vocational training, reason for unemployment, receiving living subsidies" that affect "overall learning motivation". In the multiple regression model (Model 1), the overall $F$ test did not reach significance $(F=0.44, p>.05)$, while the trainees' demographics" (including gender, marital status, age, educational attainment, relevance between past job and vocational training, number of times participating in vocational training, reason for unemployment, receiving living subsides) failed to jointly produce a significant impact on the dependent variables.

On the other hand, in the Model 2, with the effect of "background variables" on "overall learning motivation" controlled, the effect of the various aspects of "personality traits" on "overall learning motivation" was explored. The $\Delta R^{2}$ in Model 2 (model explanatory power increase) was .070 , and the $\Delta F$ value was .90 , reaching significant standard $(p<.05)$. This indicates that under the effect of the controlled "basic information", the various aspects of "personality traits" effectively affected "overall learning motivation".

The t-test results show that the regression coefficient of "openness to experience" reached significant standard $(\beta=.17, p<.05)$, the regression coefficient was a positive value, thus indicating the higher the degree of trainees' personality traits in "openness to learning", the higher the degree of overall learning motivation. On the other hand, the regional coefficients of "extraversion", "agreeableness", "conscientiousness", and neuroticism" did not reach significant standards $(p>.05)$, thus indicating the degree of the trainees' personality traits in these aspects failed to effectively affect the degree of "overall learning motivation".

Table2. The summary table of regression coefficients of demographics and personality traits of trainees affecting overall learning motivation regression coefficient

\begin{tabular}{|c|c|c|c|c|c|c|c|c|c|c|}
\hline \multirow[t]{2}{*}{ Variables } & \multicolumn{5}{|c|}{ Model 1} & \multicolumn{5}{|c|}{ Model 2} \\
\hline & $B$ & SE & $\beta$ & $t$ & $p$ & $B$ & $\mathrm{SE}$ & $\beta$ & $t$ & $p$ \\
\hline Intercept & 3.97 & 0.14 & & $29.30 * * *$ & $<.001$ & 3.58 & 0.57 & & $6.32 * * *$ & $<.001$ \\
\hline Gender(ref. female) & 0.07 & 0.06 & .07 & 1.11 & .268 & 0.09 & 0.06 & .10 & 1.59 & .112 \\
\hline \multicolumn{11}{|l|}{$\begin{array}{l}\text { Marital status } \\
\text { (ref. single) }\end{array}$} \\
\hline Married & -0.04 & 0.08 & -.05 & -0.56 & .579 & -0.05 & 0.08 & -.06 & -0.65 & .514 \\
\hline Other & 0.07 & 0.10 & .06 & 0.68 & .495 & 0.06 & 0.10 & .05 & 0.62 & .538 \\
\hline \multicolumn{11}{|l|}{$\begin{array}{l}\text { Age } \\
\text { (ref. under } 20 \text { years old) }\end{array}$} \\
\hline $21-30$ years old & 0.00 & 0.11 & .00 & 0.02 & .986 & -0.02 & 0.11 & -.02 & -0.21 & .836 \\
\hline $31-40$ years old & -0.03 & 0.12 & -.03 & -0.23 & .817 & 0.00 & 0.12 & .00 & 0.00 & .997 \\
\hline $41-50$ years old & 0.04 & 0.12 & .04 & 0.32 & .747 & 0.06 & 0.12 & .07 & 0.53 & .597 \\
\hline $51-60$ years old & 0.06 & 0.13 & .06 & 0.46 & .644 & 0.08 & 0.13 & .07 & 0.61 & .540 \\
\hline $\begin{array}{l}\text { Educational attainment } \\
\text { (ref. under junior/senior } \\
\text { high school) }\end{array}$ & -0.04 & 0.06 & -.05 & -0.73 & .463 & -0.05 & 0.06 & -.06 & -0.92 & .361 \\
\hline $\begin{array}{l}\text { Work related(ref. } \\
\text { Unrelated) }\end{array}$ & -0.03 & 0.06 & -.03 & -0.40 & .687 & 0.00 & 0.06 & .00 & 0.07 & .942 \\
\hline $\begin{array}{l}\text { Number of vocational } \\
\text { trainings(ref. first time) }\end{array}$ & 0.02 & 0.06 & .03 & 0.38 & .701 & -0.01 & 0.06 & -.01 & -0.22 & .829 \\
\hline
\end{tabular}




\begin{tabular}{|c|c|c|c|c|c|c|c|c|c|c|}
\hline $\begin{array}{l}\text { Reason for } \\
\text { unemployment } \\
\text { (ref. Involuntary) }\end{array}$ & -0.01 & 0.06 & -.01 & -0.17 & .863 & 0.03 & 0.06 & .03 & 0.42 & .672 \\
\hline $\begin{array}{l}\text { Living subsides } \\
\text { (ref. Not received) }\end{array}$ & -0.01 & 0.09 & -.01 & -0.11 & .912 & 0.00 & 0.09 & .00 & -0.05 & .959 \\
\hline \multicolumn{11}{|l|}{ Personality traits } \\
\hline Extraversion & & & & & & -0.05 & 0.07 & -.05 & -0.80 & .424 \\
\hline Agreeableness & & & & & & -0.10 & 0.06 & -.11 & -1.62 & .107 \\
\hline Conscientious & & & & & & 0.04 & 0.06 & .04 & 0.64 & .521 \\
\hline Neuroticism & & & & & & 0.07 & 0.05 & .10 & 1.45 & .148 \\
\hline Openness to experience & & & & & & 0.21 & 0.08 & .17 & $2.74 * *$ & .007 \\
\hline$\Delta R^{2}$ & & & .020 & & & & & .070 & & \\
\hline$\Delta F$ & & & 0.44 & & & & & $3.90 * *$ & & \\
\hline$\Delta p$ & & & .947 & & & & & .002 & & \\
\hline$R^{2}$ (Final) & & & .020 & & & & & .090 & & \\
\hline$F$ (Final) & & & 0.44 & & & & & 1.47 & & \\
\hline$p$ (Final) & & & .947 & & & & & .104 & & \\
\hline
\end{tabular}

Note 1. B indicates non-standardized regression coefficient, SE indicates standard error, $\beta$ indicates standardized regression coefficient.

Note 2. ref. is the reference group category

$* p<.05, * * p<.01, * * * p<.001$

\section{CONCLUSIONS AND IMPLICATIONS}

\subsection{Conclusions}

Females comprised the majority of trainees from vocational training, which is an indication of the higher ratio of women who actively participated in vocational training compared to men. In terms of age, the main age groups, the age group 21-30 years old is the main age group second only to the 4150 years old age group, indicating the increasing ratio of unemployed youth group that age is no longer the reason hindering employment. In terms of educational attainment, the senior high school/vocational high school category comprised the majority, university also took up a considerable ratio, indicating the highly educated unemployed group expects to enhance their competitiveness in the workplace through professional skills training and learning. As for whether or not past job is related to vocational training, "completely unrelated" comprised the majority. For the number of times participating in vocational training, "first time" comprised the majority, indicating the trainees expected to learn new skills and develop a second specialty. The main reason for unemployment is "voluntary employment", and most of them under this category received living subsidies.

Personality trait and learning motivation are partially significantly correlated.

It was found in this study that personality traits and learning motivation are partially significantly related. The findings also echo the argument of Winter et al. (1998). When motivation and trait interact, personal behavior will be affected. The higher the degree of trainees' "extraversion" personality trait, the lower the "job promotion" learning motivation; the higher the degree of trainees" "agreeableness" personality trait, the lower the "external motivation" learning motivation; the higher the degree of trainees" "neuroticism" personality trait, the higher the "interest for knowledge" and "external motivation" learning motivation; the higher the degree of trainees' "openness to experience", the higher the "job promotion" and "external expectations" motivation.

Under controlled demographics, personality traits are partially significantly affected. Research results show that the higher the degree of trainees' "openness to experience" personality trait, the higher the overall learning motivation. This finding coincides with the viewpoint of Barrick and Mount (1991), thus indicating the "openness to experience" personality trait, when expressed in curiosity, fondness for new things, and fondness for learning and thinking, is a key factor affecting overall learning motivation.

\subsection{Implications}

The recommendations for training units that offer vocational training for unemployed persons are:

When recruiting new trainees, their potential for learning new things should be taken into 
consideration in order to serve as a reference for assessing their learning motivation. Today's vocational training is inclined towards skills training. As previously described, Barrick and Mount (1991) believe openness to experience is an effective predictive variable for determining vocational training proficiency. Hence, when recruiting new trainees, their potential of "openness to experience" should be emphasized to enhance learning effectiveness during training.

The majority of the trainees from vocational training were females and middle-old aged. Their age and lack of confidence prevented them from learning and employment. However, the increasingly higher unemployment ratio of the youth growth must not be overlooked. Hence, functional standards, workplace attribute, and actual industrial needs should be integrated into courses, personality and occupational adaptability scale should be established, complete pre-training consultation for different genders and age groups should be provided, post-training that helps trainees further understand their personality traits and increase self-awareness should be offered, thereby helping them to identify the suitable career path, maintaining learning motivation, and equipping them with vigorous and positive and open learning attitude, thus achieving successful employment.

In terms of course design, spiritual growth related courses should be increased where appropriate in order to encourage trainees, boost their confidence, and cultivate positive thinking. As for teaching methods, in addition to the illustration and demonstration teaching of professional skills, through drama/play, break-the-ice games, group practice, teamwork, brainstorming, and other training skills, trainees' "openness to experience" personality trait can be elicited, which will in turn inspire their overall learning motivation. After training, they will be able to take initiatives to seek jobs and continue to learn after being successfully employed, thus maintaining competitiveness in the work place.

\subsection{Limitations and Recommendations}

Despite the rigorous and objective research process, there are still limitations as follows: (1) Research participants: due to time and manpower constraints, only trainees from Hualien area were adopted as research samples. It is recommended that the scope and quantity of research samples be extended in follow-up researches in order to further explore the differences among unemployed persons based on industry category, geographic location, age, and educational attainment; (2) Data analysis: The regression analysis was adopted to explore the impact of personality trait on learning motivation. However, factors affecting learning motivation are not limited to personality traits. It is recommended that empirical analysis and factor analysis be included in future research in order to find other influential factors.

\section{ACKNOWLEDGEMENTS}

Thanks for the support of funds from Ministry of Science and Technology (number of the project: NSC 102-2511-S-027-003-MY3).

\section{REFERENCES}

Briggs, S. R. (1992). Assessing the five factor model of personality description. Journal of Personality. 60(2), 253-293.

Boshier, R. (1971). Motivational orientations of adult education participants: A factor analytic exploration of Houle's typology. Adult Education Journal, 21(2), 3-26.

Chang, Chun-Hsing (1998). Educational psychology. Taipei City. Taiwan: Tung Hua Book Co., Ltd.

Chang, Jen-Chia (2013). Training and development for industry ( $3^{\text {rd }}$ ed.). Taipei City. Taiwan: Chuan Hwa Book Co., Ltd.

Chang, Jen-Chia, and Chiang, Tseng-Chang (2013). The impact of learner characteristics on transfer of training. Journal of Information Technology and Application in Education. (2)1, 16-22.

Colquitt, J. A., Lepine, J. A. and Noe, R. A. (2000).Toward an integrative theory of training motivation: a meta-analytic path analysis of 20 years of research. Journal of Applied Psychology, 35(5),678-707.

Costa, P. T., Jr. and McCrae, R. R. (1989). The neo-pi/neo-fi manual supplement. Odessa, FL: Psychological Assessment Resources

Digman, J. M. (1990). Personality structure: emergence of the five-factor model. Annual Review of Psychology, 41, 417-440. 
Directorate-General of Budget, Executive Yuan, Taiwan. (2015). Statistics of employment and unemployment. Retrieved from http://win.dgbas.gov.tw/dgbas04/bc4/timeser/comuse_a_t14.asp (accessed 14 February 2015).

Dorothea, W. A. (2013). Personality and learning motivation. European Journal of Business and Management, 5(10), Retrieved from http://pakacademicsearch.com/pdf-files/ech/517/26$38 \% 20 \mathrm{Vol} \% 205, \% 20 \mathrm{No} \% 2010 \% 20$ (2013). pdf. (accessed 10 January 2015).

Huang Fu-Shun (1996). Enhancing adult motivation to learn. Adult Education, 34, 2-8.

Hebbar, L. (2006). Vocational training for the unemployed: its impact on uncommonly served groups, International Journal of Manpower, 27(4), 377-395.

Lepper, M. R. (1985). Microcomputers in education: motivational and social issues. American Psychology, 40(1), 1-18.

Lin, N. P., Chiu, H. C., Hsieh, Y. C. (2001). Investigating the relationship between service providers' personality and customers' perceptions of service quality across gender. Total quality Management, 12(1), 57-67.

Lee, Yun-Jie, Chang, Chyi-Herng, Wang, Fang, Guo, Cheng-Chang, \& Wu, Chun-Ming (2005). Vocational training and employment security. New Taipei City, Taiwan: National Open University,

Ministry of Labor, Taiwan. (2015). The introduction of vocational training for unemployed persons. Retrieved from http://statdb.mol.gov.tw/html/mon/ 211010.htm. (accessed 20 January 2015).

McCrae, R. R. and Jone, P. O. (1992).an introduction to the five-factor model and its application. Journal of Personality, 60, 175-215.

Mount, M. K., Barrick, M. R. \& Strauss, J. P. (1994). Validity of observer ratings of the Big Five personality factors. Journal of Applied Psychology, 79, 272-281.

Major, Debra A., Turner, Jonathan E. and Fletcher, Thomas D. (2006). Linking proactive personality and the Big Five to motivation to learn and development activity. Journal of Applied Psychology, $91(4), 927-935$.

Neubäumer, R. (2012). Bringing the unemployed back to work in Germany: training programs or wage subsidies?. International Journal of Manpower,33( 2), 159-177.

Noe, R. A. (1991). Trainee characteristics and training effectiveness. In Jones, J. W., Steffy, B. D., \& Bray, W.(Eds.). Applying psychology in business:The handbook for managers and human resource professionals. Lexington, MA: Lexington Books.

Research Development and Evaluation Commission, Executive Yuan, Taiwan (2012). A study of youth and middle-old aged labor force employment in Taiwan. Taipei City, Taiwan: Research Development and Evaluation Commission, Executive Yuan.

Saucier, G. (1994). Mini-markers: a brief version of Goldberg's unipolar Big-Five markers. Journal of Personality Assessment, 63(3), 506-616.

Salgado, J. F. (1997). The five factor model of personality and job performance in the European community. Journal of Applied Psychology, 82,30-43.

Tan, Yang-kuang (2012). Vocational training theory and practice. New Taipei City, Taiwan: Hsincheng.

Tharenou, P. (2001). The relationship of training motivation to participation in training and development. Journal of Occupational \& Organizational Psychology, 74(5), 599-621.

Tracey, J. B., \& Tews, M. J. (1995). Training effectiveness: accounting for individual characteristics and the work environment. Cornell Hotel and Restaurant Administration quarterly, 36( 6), 3642.

Winter, D. G., John, O. P., Stewart, A. J., Klohnen, E. C. \& Duncan, L. E. (1998). Traits and motives: Toward an integration of two traditions in personality research. Psychological Review, 4, 230250.

$\mathrm{Wu}$, Ming-Lung (2009). SPSS operation and application-the practice of quantitative analysis of questionnaire data ( $2^{\text {nd }}$ ed.). Taipei City, Taiwan: Wu-Nan Culture Enterprise. 


\section{AUTHORS'BIOGRAPHY}

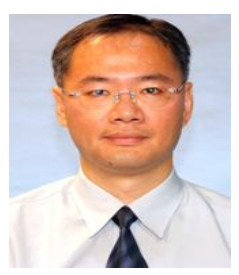

Chang, Jen-Chia, Dr., gained a BEd in Industrial Education in 1991 from National Taiwan Normal University, an MA in Human Resource Management in 1994 and a $\mathrm{PhD}$. in Industrial Education in 2000 from National Changhua University of Education. Currently, he is a professor in Institute of Vocational and Technological Education in National Taipei University of Technology and his teaching subjects are school innovation and management. Mr. Jen-Chia Chang has taught for ten years at industrial vocational high school and thirteen years at university of technology. Jen-Chia Chang is also a member of some professional organizations, he has authored more than 200 articles and papers, and his work had published in U.S., Hong Kong, Taiwan, and other countries. His research has focused on innovation management of vocational and technological education and engineering education.

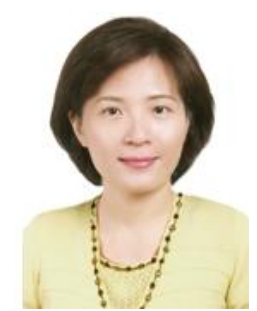

Chiang, Po-Ying, Master degree. Graduate institute of Art, Chinese Culture University, Taiwan. $\mathrm{PhD}$ candidate, Graduate Institute of Technological and Vocational Education, National Taipei University of Technology, Taiwan. She has taught and shared her professional knowledge in beauty \& cosmetic, and aromatherapy at various colleges and universities over the past decade. She has also served as a consultant in national beauty and cosmetic competitions, providing trainings, executing designed programs and curriculums as a lecturer of the vocational department, ministry of labor, Taiwan. She majors her researches in vocational training, education in styling design, and analysis in cosmetic products. She also a corresponding author in this study. 